\title{
Practice variation across consent templates for biobank research. A survey of German biobanks
}

\section{Irene Hirschberg, Hannes Knüppel and Daniel Strech*}

Hannover Medical School, Institute for History, Ethics and Philosophy of Medicine / Centre for Ethics and Law in the Life Sciences, Hannover, Germany

\section{Edited by:}

Aaron J. Goldenberg, Case Western Reserve University, USA

\section{Reviewed by:}

Ma'N H. Zawati, Centre of Genomics and Policy, Canada

Katharina Beier, University Medical

Center Goettingen, Germany

\section{*Correspondence:}

Daniel Strech, Hannover Medical

School, Institute for History, Ethics and Philosophy of Medicine / Centre for Ethics and Law in the Life Sciences, Carl-Neuberg-Strasse 1, 30625 Hannover, Germany

e-mail: strech.daniel@mh-hannover.de

\begin{abstract}
Introduction: Informed, voluntary, and valid consent from biomaterial donors is a precondition for biobank research. Valid consent protects donors' rights and helps maintain public trust in biobank research. Harmonization of consent procedures in biobank research is needed, because of the widely shared vision on national and international networking of biobanks including data and sample sharing. So far, no study has assessed and compared the content of current consent forms especially for biobank research. The objective of this study was to perform a content analysis of consent forms in German biobanks.
\end{abstract}

Methods: Based on ten guidelines for biomedical research, we developed an assessment matrix with 41 content issues that are potentially relevant for consent forms in biobank research. This assessment matrix was applied in a thematic text analysis to 30 consent documents of German biobanks identified via the German Biobank Registry in July 2012.

Results: Coverage of the 41 items in the assessed consent forms varied widely. For example, the items "Right to withdraw consent (without disadvantage)," "Policy for genetic information/consent to genetic analyzes" and "International cooperation/transborder use" were addressed in 97,40 , and $23 \%$ of all 30 consent forms respectively. The number of items covered by a single consent form ranged from 9 to 36 (22-88\% out of 41 items).

Discussion: Our findings serve as a starting point to reflect upon the spectrum of consent issues that must be addressed in biobank research. The findings show that the majority of consent forms for German biobanks, if not all, should be improved and harmonized to better support an informed and balanced choice of potential donors and to facilitate networking of biobanks. Best practice models for consent forms in biobank research should be developed and biobank operators need to be more aware of relevant consent issues.

Keywords: biobank, tissue bank, broad consent, informed consent, survey, thematic text analysis, research ethics

\section{INTRODUCTION}

Biobanks are collections of human biological samples and related health/personal information. A high quality biobank that organizes samples for use by biomedical researchers is seen as an important resource for health research, including basic research, questions in personalized or stratified medicine (genetic and other biomarkers), and research in widespread diseases (Asslaber and Zatloukal, 2007; Zika et al., 2010).

The development of large-scale population-based as well as disease-specific biobanks also implies several new ethical, legal and social challenges. These comprise, e.g., issues around the role of ethics committees, data protection, dealing with incidental findings, public involvement measures, and particularly regarding the need for new or at least modified models of informed consent of the donors (Budimir et al., 2011; Gottweis and Kaye, 2012). As acquired for diagnostic and therapeutic procedures in clinical as well as in research settings, informed, voluntary, and valid consent is a precondition for the collection of samples and clinical data of donors in a biobank. It also tends to protect donors' rights and autonomy and to maintain public trust in biobank research. Crucial points include the scope and content of consent forms, for example, how do consent forms address potential future research projects that might involve the donated biomaterials (broad/general vs. narrow/specific consent) (Cambon-Thomsen et al., 2007; Greely, 2007; Hansson, 2009; OECD, 2009; Budimir et al., 2011; Deutscher Ethikrat, 2011). Additionally, biobank research consent procedures and documentation involve different or additional aspects compared with clinical research, e.g., concerning data protection and data sharing with other researchers (Hoeyer et al., 2005; Beskow et al., 2010; McGuire and Beskow, 2010; Pawlikowski et al., 2011). Besides, the harmonization of consent templates, at least of the most important criteria, is essential for future cooperation and networking at the national and international level.

Though information and consent documents do certainly not substitute the discussion between clinician/researcher and patient/participant, they are an important component within the informed consent procedure and its documentation, as well as for legal aspects. Regarding quality and performance of consent forms in clinical or research contexts, several empirical studies demonstrated that consent forms are often not adequate in content, comprehensibility or practicability and do not meet 
participants' needs. Improvements are necessary within consent procedure and documents to support an adequately well-balanced and evidence-based decision-making process by participants (Jefford and Moore, 2008; Padhy et al., 2011; Brehaut et al., 2012; Mandava et al., 2012).

Several sets of ethical guidance define the required criteria for consent in clinical research, e.g., (Council for International Organizations of Medical Sciences [CIOMS], 2002; World Medical Association [WMA], 2008). Some guidelines also explicitly mention required criteria for consent in biobank research, e.g., (OECD, 2009). Nevertheless, there is no specific guidance for biobank research and consent procedures that can be employed as a tool for the assessment of consent forms' content in clinical or biobank research. Furthermore, we currently lack a broadly accepted "best practice" model for consent forms in biobank research (Gottweis and Kaye, 2012).

Also in Germany, the number and importance of biobank facilities and projects with similar requirements is increasing, e.g., in population-wide studies such as KoraGEN and PopGEN, and the National Biobank Initiative ("Nationale Biomaterialbanken Initiative") funded by the German Federal Ministry of Education and Research (Bundesministerium für Bildung und Forschung, BMBF).

Existing studies that describe different biobanks and their governance strategies also indicate challenges in consent procedures (Hirtzlin et al., 2003; Zika et al., 2010; Gottweis and Kaye, 2012). Some research groups propose a unified consent model or possible content for a consent form in biobank research (Porteri and Borry, 2008; Salvaterra et al., 2008) or for whole genome sequencing studies in the clinical context (Ayuso et al., 2013). Besides, there are studies comparing participant information and consent forms in genetic research (Mascalzoni et al., 2010) or in clinical trials (Hüppe et al., 2013). But so far, no study has assessed and compared the content of consent forms for biobank research. The objective of this study was to perform a survey and content analysis of currently used consent forms in German biobanks.

\section{MATERIALS AND METHODS}

To improve the comprehensiveness, reliability, validity, and objectivity of our assessment of biobank specific consent forms, we first systematically developed an assessment matrix of potentially relevant issues that might be addressed in consent documents for biobank research. We then applied this assessment matrix to a sample of consent forms from German biobanks.

\section{DEVELOPMENT OF THE ASSESSMENT MATRIX}

To identify issues that might be addressed in consent documents for biobank research, we referred to frequently cited policies, guidelines, and regulations dealing with general recommendations for consent procedures in biomedical research (mainly clinical studies) and/or biobank research. More specifically, we used nine prominent guidelines for biomedicine (Council of Europe, 1997), biomedical research with humans in general (European Parliament and the Council of the European Union, 2001; Council for International Organizations of Medical Sciences [CIOMS], 2002; European Medicines Agency [EMEA], 2002; Council of Europe, 2005; World Medical Association [WMA], 2008; US Department of Health and Human Services, 2009), and biobank or biomaterial research in particular (Council of Europe, 2006; OECD, 2009). For the national (German) context, we referred to a "commented checklist" of issues in patient information and consent for clinical studies with an annex for biobank research (Harnischmacher et al., 2006). The set of selected guideline is a purposive sample. Most of the chosen guidelines are, for instance, indicated as important legal and ethical frameworks in other sources such as the Oxford Textbook of Clinical Research Ethics (Capron, 2008; Emanuel et al., 2008). We have discussed the selection of guidelines and the resulting construct validity of the matrix of consent issues internally and with experts from the fields of law and biobank research.

In all ten documents, one author (Irene Hirschberg) searched for text passages that explicitly or implicitly mentioned issues of potential relevance to the content of consent forms in biomedical research in general, and applicable to biobank research. Examples mentioned as necessary information for consent included "general procedures and safeguards used to protect privacy and confidentiality," the "policy with respect to benefit sharing" and "information on the human biological material and data to be collected, their intended uses, storage, transfer and their disposal technique" (OECD, 2009). An example for a relevant but implicitly mentioned issue dealt with the removal of biological materials after death: "biological materials should not be removed from the body of a deceased person for research activities without appropriate consent or authorisation." (Council of Europe, 2006) Other issues were mentioned only in relation to the research protocol, such as "incentives for subjects" (World Medical Association [WMA], 2008)," or came under the discussion of policy, but indicated as relevant to participants: "The HBGRD's policy should also address the situation where participants become legally incapacitated or die. It is essential that the HBGRD provide information on their policy to the participant or the appropriate substitute decision-maker at the time of consenting." (OECD, 2009) The results and any ambiguity were discussed with the other authors (Hannes Knüppel and Daniel Strech). We excluded generally important aspects of biomedical research that were mentioned in one or more guidelines but were not considered relevant to the content of consent forms in biobank research, e.g., "trial treatment and random assignment (European Medicines Agency [EMEA], 2002)" and "alternative procedures or courses of treatment" (US Department of Health and Human Services, 2009). We also excluded formal aspects such as "title of the document" or "date/signature" (Harnischmacher et al., 2006).

We compared the mentions of issues relevant to consent forms in biobank research in different guidelines, and developed categories for similar mentions of issues. During the development of these categories, we slightly adapted the items arising from the clinical study context to the biobank context. For instance, we revised the wording "duration of participation in trial/study" to "duration of participation or storage." In some cases we performed a synthesis of issues, e.g., subsuming "money or material goods" (Council for International Organizations of Medical Sciences [CIOMS], 2002), "payment" and "expenses" (European Medicines Agency [EMEA], 2002), "additional costs" (US Department of Health 
and Human Services, 2009), "incentives" (World Medical Association [WMA], 2008), and "allowance" (Harnischmacher et al., 2006) under "Payment/allowance and additional costs." We finally obtained 41 items grouped under four main headings (see Results and Table 1). Each of the 41 items derives from at least two guidance documents.

\section{BIOBANK SURVEY AND ANALYSIS OF THE CONSENT DOCUMENTS}

To get an overview of consent documents and templates currently used in biobank research in Germany, we considered all biobanks registered in the German Biobank Registry ("Deutsches Biobanken-Register," http://www.biobanken.de) in July 2012. We excluded six of the 108 registered biobanks because they were either doubly mentioned in the register or did not exist anymore (or their web site could not be accessed). Nine of the remaining 102 biobanks had consent forms publically available on their websites. We asked the heads of the other 93 biobanks via email to send us their consent documents. In this email we made clear that German biobanks will not be named individually in the dissemination of findings from our study. The response rate after repeated contact was $48 \%$ (44/90 biobanks, three mailing addresses were incorrect). Not all biobanks were willing to provide their consent document; some biobanks used a shared consent form, and two biobanks provided two documents for different purposes. At last, we were able to include 30 consent documents of 33 biobanks in our analysis. If the biobanks provided additional participant information and a consent form, we included both documents in the analysis.

The representation of all 41 items in each of the 30 consent documents was assessed according to standards in thematic text analysis (Dixon-Woods et al., 2005). All researchers were experienced in thematic text analysis and research ethics. The consent forms were read in full by two authors (Irene Hirschberg and Hannes Knüppel) independently to identify and extract text passages corresponding to each of the 41 consent issues for biobank research. For the purpose of this study the authors only rated whether the items were mentioned or not. For example, the authors did not evaluate in depth whether these items were sufficiently comprehensible. After the independent text extraction and rating the researchers compared their results. Discrepancies between the resulting spreadsheets were identified in 114 (9.3\%) of all 1,230 ratings (41 ratings for each of the 30 consent forms). These discrepancies were discussed and resolved with the third author (Daniel Strech).

\section{RESULTS}

\section{ASSESSMENT MATRIX}

Our assessment matrix comprises 41 items in four categories: (A) "General information" covering, e.g., explanation of the type of research and its purpose, (B) "Conditions of participation" including background on voluntary participation, consent conditions and scope, $(\mathrm{C})$ "Consequences of participation" comprising items on, e.g., risks and benefits, and (D) "Dealing with data and biomaterial" encompassing items on, e.g., data protection measures and cooperation with other parties. Table 1 presents the 41 items of the assessment matrix for consent in biobank research, the number of guidance sets from which each item derived, and the extent to which the items were mentioned in the German biobank sample (see Table 1).

\section{GERMAN CONSENT DOCUMENTS FOR BIOBANK RESEARCH}

Our sample comprised 30 consent documents from 33 German biobanks registered in the German Biobank Registry in July 2012. The sample includes different types of biobank with varying characteristics as type (population-wide or disease-specific biobank, or clinical study with sample collections), number of participants, organization and funding, and inclusion of healthy probands or patients (e.g., inclusion of all admitted patients). However, all registered biobanks are considered to perform biobank research. The German Biobank Registry is operated by the TMF (Technology, Methods, and Infrastructure for Networked Medical Research) and is funded by the German Federal Ministry of Education and Research.

Most of the biobanks had developed their own consent documents; one biobank just used a consent form for genetic diagnostic similar to a template of the German Society of Human Genetics. The consent documents (participant information and consent form) varied in several characteristics, e.g., in length of document (one to five pages), target group (patient, healthy participant, next kin, children, or parents), scope of consent, content, complexity and comprehensibility.

The coverage of the 41 items by the 30 consent documents was very variable. One item ("Right to withdraw or alter consent (without disadvantage)") was addressed in $97 \%$, another item ("Dealing with data and material after participants die or become incapacitated") was not addressed by any consent form (see Table 1). Though for the interpretation of the results, it has to be considered that a few items - as "Removal of samples after death" - are not applicable to all biobanks. Nevertheless, in these cases the items were counted as "not mentioned".

A large majority of the German consent documents referred to items as in section (A) such as e.g., "Research explanation and purpose" (93\%) and "Biomaterial: types and quantity of specimen" $(90 \%)$, to elementary conditions in (B) such as "Free and voluntary participation" (80\%) or "Right to withdraw or alter consent (without disadvantage)" (97\%) and to basic aspects in section (D) such as "Confidentiality of records and data/extent and limits of confidentiality" (80\%) and "Privacy rights and procedures/safeguards, data processing, and identifiability of data and samples" (90\%).

Information on some controversially discussed or partly not foreseeable items was given less frequently e.g., for general information (section (A)) such as "Future development and changes" (30\%) or information on "Rights/Ownership of samples and data and their transfer" (57\%). Also some points regarding the conditions of participation (section (B)) were considered by just half of the documents, e.g., "Decision on participation/withdrawal without affecting medical care or relationship to physician" (50\%) or "Options/partial consent" (53\%). Of the items regarding the consequences of participation (section (C)), the most mentioned was "Risk" (70\%) and the least-mentioned "Payment/Allowance or additional costs" (33\%). The mentioning of risks ranged from: no any mentioned risks at all over minimal risks for the sample/bloodtaking procedure to a very detailed description of the risks using genetic data. (The latter refer to for example the knowledge as 
Table 1 | Representation of 41 consent issues for biobank research in 30 German consent documents.

\section{Consent issues for biobank research}

\section{Assessment items}

\section{(A) General information}

Research explanation and purpose

Future development and changes

Biobank design and structure

Funding and (conflict of) interests

Duration of participation or storage

Biomaterial: types and quantity of specimen

Data: type and quantity of data

Description of collection procedures and

additional tests

Sample collection: further examination

needed/follow up-points

Rights/ownership of samples and data and

their transfer

Opinion or approval of ethical review

board/committee

\section{(B) Conditions of participation}

Dimension of consent: scope, safeguards and

Origin: mention in guidelines for the

conditions

Free and voluntary participation

Right to withdraw or alter consent (without

disadvantage)

Withdrawal: modalities and consequences

regarding biomaterial and data

Decision on participation/withdrawal without

affecting medical care or relationship to

physician

Compensation and insurance cover

Options (partial consent)

\section{(C) Consequences of participation}

Direct benefit for participant

Indirect benefit for subgroups or society

Risk

Payment/allowance or additional costs

Benefit-sharing

Feedback on findings or incidental findings

Publication of data only unlinked

Re-contacting of participant: purpose and conditions

Contact person/point regulation of biomedical research $(n=10)$

n $\quad \%$

10

5

5

6

7

3

3

8

2

2

5

10

100

50

50

60

70

30

30

80

20

20

50

Application: mention in biobank-specific

consent documents $(n=30)$

\section{n}

$\%$

93

30

70

20

50

90

63

87

26

23

77

17

57

53
5

16

15

19

21

10

18

20

17

18

18
17

53

50

63

70

33

60

67

57

60

60 
Table 1 | Continued

\begin{tabular}{|c|c|c|c|c|}
\hline \multirow{2}{*}{$\begin{array}{l}\text { Consent issues for biobank research } \\
\text { Assessment items }\end{array}$} & \multicolumn{2}{|c|}{$\begin{array}{l}\text { Origin: mention in guidelines for the } \\
\text { regulation of biomedical research }(n=10)\end{array}$} & \multicolumn{2}{|c|}{$\begin{array}{l}\text { Application: mention in biobank-specific } \\
\text { consent documents }(n=30)\end{array}$} \\
\hline & $n$ & $\%$ & $n$ & $\%$ \\
\hline \multicolumn{5}{|l|}{ (D) Dealing with data and biomaterial } \\
\hline $\begin{array}{l}\text { Confidentiality of records and data/extent and } \\
\text { limits of confidentiality }\end{array}$ & 9 & 90 & 24 & 80 \\
\hline $\begin{array}{l}\text { Privacy rights and procedures/safeguards, data } \\
\text { processing, and identifiability of data and } \\
\text { samples }\end{array}$ & 6 & 60 & 27 & 90 \\
\hline $\begin{array}{l}\text { Use of health data and records and their } \\
\text { purpose }\end{array}$ & 3 & 30 & 20 & 67 \\
\hline Storage of data and biomaterial & 3 & 30 & 20 & 67 \\
\hline $\begin{array}{l}\text { Policy for genetic information/consent to } \\
\text { genetic analyses }\end{array}$ & 2 & 20 & 12 & 40 \\
\hline $\begin{array}{l}\text { Contact with or disclosure to participant's } \\
\text { physician }\end{array}$ & 2 & 20 & 19 & 63 \\
\hline $\begin{array}{l}\text { Policy on use/disclosure to third parties for } \\
\text { non-research purpose }\end{array}$ & 3 & 30 & 7 & 23 \\
\hline $\begin{array}{l}\text { Sharing data and material with other } \\
\text { researchers/policy and process }\end{array}$ & 2 & 20 & 24 & 80 \\
\hline International cooperation/trans-border use & 2 & 20 & 7 & 23 \\
\hline $\begin{array}{l}\text { Commercialisation and collaboration with } \\
\text { for-profit entities }\end{array}$ & 5 & 50 & 17 & 57 \\
\hline Right of access to personal data & 3 & 30 & 5 & 17 \\
\hline Disposal or destruction of data and material & 3 & 30 & 21 & 70 \\
\hline $\begin{array}{l}\text { Dealing with data and material after } \\
\text { participants die or become incapacitated }\end{array}$ & 2 & 20 & 0 & 0 \\
\hline Removal of material after death & 2 & 20 & 1 & 3 \\
\hline
\end{tabular}

such and the related psychological burdens for the donor or family members, implication on re-identifiability of "anonymized" data, and potential implications on health insurance and employment).

Some items of presumably high importance for biobank research (in section (D) "Dealing with data and biomaterial") were mentioned infrequently, e.g., "International Cooperation/transborder use" (23\%), "Right of access to personal data" (17\%) or "Policy on use/disclosure to third parties for non-research purpose" (23\%).

The number of items found also varied widely among the 30 consent documents (see Table 2), from a minimum of $9(22 \%)$ to a maximum of $36(88 \%)$. The median of items addressed across all 30 consent forms was 25.5 items $(62 \%)$.

\section{DISCUSSION AND CONCLUSION}

This study illustrates that consent documents from 30 German biobanks differ widely in the range of issues that they address. Out of 41 potentially relevant issues (systematically identified in
Table 2 | Distribution of assessment items ( $n=41$, divided into five ranges) for consent content in biobank research, found in consent documents of a German biobank sample $(n=30)$.

\begin{tabular}{llll}
$\begin{array}{l}\text { Assessment items for consent } \\
\text { in biobank research }\end{array}$ & & \multicolumn{2}{l}{$\begin{array}{l}\text { Mention in German biobank } \\
\text { consent documents }\end{array}$} \\
\cline { 1 - 1 } Range & & $\mathbf{n}$ & $\%$ \\
\hline 33-41 (approx. 80-100\%) & 3 & 10 \\
25-32 (approx. 60-80\%) & & 14 & 47 \\
17-24 (approx. 40-60\%) & 6 & 20 \\
9-16 (approx. 20-40\%) & 7 & 23 \\
0-8 (approx. 0-20\%) & 0 & 0 \\
\hline
\end{tabular}

leading guidelines on consent in biomedical research) only three consent forms (10\%) address more than $80 \%$ while another seven consent forms (23\%) address less than $40 \%$. 
One should bear in mind that the consideration of more items does not facilitate consent or increase its validity per se. Nevertheless, one should have reasonable motives to minimize the extent of content and leave out relevant items.

With respect to the existing heterogeneity and different types of biobanks, it has to be considered that not all of the mentioned items must be applicable or equally relevant to each biobank. Nevertheless, core criteria for consent in biobank research and could be harmonized on an at least abstract level. Such abstract templates could then be adapted to the individual national or local context. In the German sample it is remarkable that items with a presumably high significance for biobank research in general (Cambon-Thomsen et al., 2007; Hansson, 2009; OECD, 2009; Budimir et al., 2011) were mentioned in less than $25 \%$ of all consent forms, e.g., "International Cooperation/trans-border use," "Right of access to personal data" and "Policy on use/disclosure to third parties for non-research purpose." The low coverage of such issues in consent forms may be partly because new developments in data protection law and research agendas are not foreseeable in detail. But it may be also because of a still limited awareness of legal, ethical, and practical challenges in biobank research and the need for their transparent communication to potential participants (Gottweis and Kaye, 2012).

Concerning the complexity of information, empirical studies need to assess which potentially relevant content issues for consent forms in biobank research can be condensed or simplified without minimizing the validity of the consent and the tissue donors' understanding of biobank research. For a first step in this direction see Beskow (Beskow et al., 2010).

Our study has the following limitations: as a demand of further research it would be worthwhile to expand or modify the guidance-based assessment matrix for consent in biobank research in the following way: (1) to define a set of core criteria or balance the assessment items regarding their importance or relevance, (2) to outline explaining dimensions for these items, and (3) to further analyze which aspects are not covered sufficiently by the matrix respectively by the included guidances (e.g., diagnostic/therapeutic misconception). Such conceptual and empirical research would provide the basis for a deeper evaluation of existing consent documents and for the development of new consent documents. Within our explorative study of German biobank consent documents we only considered whether a potentially relevant content issue was mentioned in a consent form at all. We evaluated neither the accuracy of the explanation of this issue nor its quality, comprehensibility, or readability. Furthermore, we did not assess criteria for supportive decision-making (e.g., IPDAS-criteria IPDAS, 2005; Elwyn et al., 2006). These assessment criteria are certainly important for the development and evaluation of valid consent procedures as shown e.g., by (Beskow et al., 2010; Brehaut et al., 2012). Another limitation arises from the fact that we could only include $32 \%$ of consent forms from the full sample of 102 biobanks registered in the German Biobank Registry. However, our sample of 30 consent forms included all leading German biobanks with relatively high quality standards (including all six biobanks that are part of the National Biobank Initiative funded by the German Federal Ministry of Education and Research, BMBF). We suppose that the inclusion of further consent forms would not have changed the overall picture of the strong heterogeneity of consent forms for biobank research. Moreover, we would even expect a wider variation in content issues. Other investigations have reached similar results and support the finding that consent material in general, or in biomedical and biobank research in particular, needs improvement (Padhy et al., 2011; Pawlikowski et al., 2011; Brehaut et al., 2012; Mandava et al., 2012).

Taking into account the widely shared vision of national and international networking of biobanks and increased activities in data and sample sharing, our findings demonstrate the need of improvement and harmonization of consent procedures in the field of biobank research. Furthermore, such improvements are important to fulfil the demand of responsible biobank governance and to maintain public trust in biobank research (Gottweis and Kaye, 2012). This does also include transparent communication on consent procedures. As described in the methods section only nine consent templates $(8.8 \%)$ of the 102 initially identified biobanks were available publically on the biobanks' web sites. Furthermore, even after repeated contact and the guarantee to anonymize the results for our assessment of consent forms only 32\% of registered German biobanks were willing to provide their present consent form. Beside the need to improve and harmonize consent procedures, increased transparency of such basic information should become a major aim of German biobanks, to demonstrate appropriate standards of governance.

When it comes to future improvement and harmonization of consent forms, public attitudes and expert opinion in relevant fields such as law, ethics, medicine, natural science etc. should be sought to define core criteria for consent. It may also help to overcome the lack of awareness of potentially relevant consent items and to address them in an appropriate way.

\section{CONCLUSION}

Our findings serve as a starting point to reflect upon the spectrum of relevant consent issues in biobank research. The present study supports the systematic and transparent development of a "best practice" model of consent for biobank research. The findings show that at least the majority of consent documents in German biobanks should be improved and harmonized to better support an informed and balanced choice by potential donors and to facilitate research cooperation and networking. Further steps of such a best practice model would include the development of a best practice consent template (considering content, adherence to quality and language criteria) followed by a discussion and review of the template with other stakeholders (e.g., researchers, research ethics committees, potential biobank participants, patients' representatives, and ethicists). Especially for a best practice model for consent forms, the understanding and validity of the text should be tested empirically (Sugarman et al., 2005; Flory et al., 2008). Finally, its use should be accompanied by continuous evaluation.

\section{REFERENCES}

Asslaber, M., and Zatloukal, K. (2007). Biobanks: transnational, European and global networks. Brief. Funct. Genomic Proteomic. 6, 193-201. doi: 10.1093/bfgp/elm023 
Ayuso, C., Millan, J. M., Mancheno, M., and Dal-Re, R. (2013). Informed consent for whole-genome sequencing studies in the clinical setting. Proposed recommendations on essential content and process. Eur. J. Hum. Genet. 21, 1054-1059. doi: 10.1038/ejhg.2012.297

Beskow, L. M., Friedman, J. Y., Hardy, N. C., Lin, L., and Weinfurt, K. P. (2010) Developing a simplified consent form for biobanking. PLoS ONE 5:e13302. doi: 10.1371/journal.pone.0013302

Brehaut, J. C., Carroll, K., Elwyn, G., Saginur, R., Kimmelman, J., Shojania, K., et al. (2012). Informed consent documents do not encourage good-quality decision making. J. Clin. Epidemiol. 65, 708-724. doi: 10.1016/j.jclinepi.2012.01.004

Budimir, D., Polasek, O., Marusic, A., Kolcic, I., Zemunik, T., Boraska, V., et al. (2011). Ethical aspects of human biobanks: a systematic review. Croat. Med. J 52 262-279. doi: 10.3325/cmj.2011.52.262

Cambon-Thomsen, A., Rial-Sebbag, E., and Knoppers, B. M. (2007). Trends in ethical and legal frameworks for the use of human biobanks. Eur. Respir. J. 30, 373-382. doi: 10.1183/09031936.00165006

Capron, A. M. (2008). "Legal and regulatory standards of informed consent in research," in Oxford Textbook of Clinical Research Ethics, eds E. J. Emanuel, C. Grady, R. A. Crouch, R. K. Lie, F. G. Miller, and D. Wendler (Oxford: Oxford University Press), 613-632.

Council for International Organizations of Medical Sciences [CIOMS]. (2002) International Ethical Guidelines for Biomedical Research Involving Human Subjects. Geneva: CIOMS. Available at: http://www.cioms.ch/publications/guidelines/ guidelines_nov_2002_blurb.htm

Council of Europe. (1997). Convention for the Protection of Human Rights and Dignity of the Human Being with Regard to the Application of Biology and Medicine: convention on Human Rights and Biomedicine. Strasbourg: Council of Europe. Available at: http://conventions.coe.int/Treaty/EN/Treaties/Html/ 164.htm

Council of Europe. (2005). Additional Protocol to the Convention on Human Rights and Biomedicine Concerning Biomedical Research. Strasbourg: Council of Europe. Available at: http://conventions.coe.int/treaty/en/Treaties/Html/195.htm

Council of Europe. (2006). Recommendation Rec (2006)4 of the Committee of Ministers to member states on research on biological materials of human origin. Strasbourg: Council of Europe. Available at:https://wcd.coe.int/ViewDoc.jsp? id $=977859 \&$ BackColorInternet $=9999$ CC $\&$ BackColorIntranet $=$ FFBB55\&Back ColorLogged $=$ FFAC75

Deutscher Ethikrat. (2011). Humanbiobanken für die Forschung. Berlin: Deutscher Ethikrat.

Dixon-Woods, M., Agarwal, S., Jones, D., Young, B., and Sutton, A. (2005). Synthesising qualitative and quantitative evidence: a review of possible methods. $J$ Health Serv. Res. Policy 10, 45-53. doi: 10.1258/1355819052801804

Elwyn, G., O'connor, A., Stacey, D., Volk, R., Edwards, A., Coulter, A., et al. (2006). Developing a quality criteria framework for patient decision aids: online international Delphi consensus process. BMJ 333, 417. doi: 10.1136/bmj.38926.629329.AE

Emanuel E. J., Grady C, Crouch R. A., Lie R. K., Miller F. G., and D. Wendler. (2008) Oxford Textbook of Clinical Research Ethics. Oxford: Oxford University Press.

European Medicines Agency [EMEA]. (2002). CPMP/ICH/135/95 Guideline for Good Clinical Practice, ICH Topic E 6 (R1). London: European Medicines Agency. Available at: http://www.emea.europa.eu/docs/en_GB/document_library/ Scientific_guideline/2009/09/WC500002874.pdf

European Parliament and the Council of the European Union. (2001). Directive 2001/20/EC on the Approximation of the Laws, Regulations and Administrative Provisions of the Member States Relating to the Implementation of Good Clinical Practice in the Conduct of Clinical Trials on Me-dicinal Products for Human Use, Luxembourg. Available at: http://eur-lex.europa.eu/LexUriServ/LexUriServ. do?uri=OJ:L:2001:121:0034:0044:EN:PDF

Flory, J. H, Wendler. D., and Emanuel, E. (2008). "Empirical issues in informed consent for research," in Oxford Textbook of Clinical Research Ethics, eds E. J. Emanuel, C. Grady, R. A. Crouch, R. K. Lie, F. G. Miller, and D. Wendler (Oxford: Oxford University Press), 645-660.

Gottweis, H., and Kaye, J. (2012). Biobanks for Europe: A Challenge for Governance. Report of the Expert Group on Dealing with Ethical and Regulatory Challenges of International Biobank Research. Luxembourg: European Commission.

Greely, H. T. (2007). The uneasy ethical and legal underpinnings of largescale genomic biobanks. Annu. Rev. Genomics Hum. Genet. 8, 343-364. doi 10.1146/annurev.genom.7.080505.115721
Hansson, M. G. (2009). Ethics and biobanks. Br. J. Cancer 100, 8-12. doi: 10.1038/sj.bjc.6604795

Harnischmacher, U., Ihle, P., Berger, B., Goebel, J., and Scheller, J. (2006). Checkliste und Leitfaden zur Patienteneinwilligung. Grundlagen und Anleitung für die Klinische Forschung. Berlin: Medizinisch Wissenschaftliche Verlagsgesellschaft.

Hirtzlin, I., Dubreuil, C., Preaubert, N., Duchier, J., Jansen, B., Simon, J., et al. (2003). An empirical survey on biobanking of human genetic material and data in six EU countries. Eur. J. Hum. Genet. 11, 475-488. doi: 10.1038/sj.ejhg.52 01007

Hoeyer, K., Olofsson, B. O., Mjorndal, T., and Lynoe, N. (2005). The ethics of research using biobanks: reason to question the importance attributed to informed consent. Arch. Intern. Med. 165, 97-100. doi: 10.1001/archinte.165. 1.97

Hüppe, A., Dziubek, K., and Raspe, H. (2013). Zum Verbesserungspotenzial schriftlicher Aufklärungsmaterialien zu (bio)medizinischen Forschungsvorhaben - Empirische Analyse von Antragsunterlagen einer Forschungsethikkommission. Ethik Med. doi: 10.1007/s00481-013-0257-5 [Epub ahead of print].

IPDAS. (2005). "Criteria for judging the quality of patient decision aids. Checklist," in International Patient Decision Aids Standards (IPDAS) Collaboration. Available at: http://ipdas.ohri.ca/IPDAS_checklist.pdf

Jefford, M., and Moore, R. (2008). Improvement of informed consent and the quality of consent documents. Lancet Oncol. 9, 485-493. doi: 10.1016/S14702045(08)70128-1

Mandava, A., Pace, C., Campbell, B., Emanuel, E., and Grady, C. (2012). The quality of informed consent: mapping the landscape. A review of empirical data from developing and developed countries. J. Med. Ethics 38, 356-365. doi: 10.1136/medethics-2011-100178

Mascalzoni, D., Janssens, A. C., Stewart, A., Pramstaller, P., Gyllensten, U., Rudan, I., et al. (2010). Comparison of participant information and informed consent forms of five European studies in genetic isolated populations. Eur. J. Hum. Genet. 18, 296-302. doi: 10.1038/ejhg.2009.155

McGuire, A. L., and Beskow, L. M. (2010). Informed consent in genomics and genetic research. Annu. Rev. Genomics Hum. Genet. 11, 361-381. doi: 10.1146/annurevgenom-082509-141711

OECD. (2009). Guidelines on Human Biobanks and Genetic Research Databases. Paris: Organisation for Economic Co-Operation and Development (OECD). Avaialble at: http://www.oecd.org/sti/biotech/44054609.pdf

Padhy, B. M., Gupta, P., and Gupta, Y. K. (2011). Analysis of the compliance of informed consent documents with good clinical practice guideline. Contemp. Clin. Trials 32, 662-666. doi: 10.1016/j.cct.2011. 05.016

Pawlikowski, J., Sak, J., and Marczewski, K. (2011). Biobank research and ethics: the problem of informed consent in Polish biobanks. Arch. Med. Sci. 7, 896-901. doi: 10.5114/aoms.2011.25568

Porteri, C., and Borry, P. (2008). A proposal for a model of informed consent for the collection, storage and use of biological materials for research purposes. Patient Educ. Couns. 71, 136-142. doi: 10.1016/j.pec.2007.12.003

Salvaterra, E., Lecchi, L., Giovanelli, S., Butti, B., Bardella, M. T., Bertazzi, P. A., et al. (2008). Banking together. A unified model of informed consent for biobanking. EMBO Rep. 9, 307-313. doi: 10.1038/embor. 2008.41

Sugarman, J., Lavori, P. W., Boeger, M., Cain, C., Edsond, R., Morrison, V., et al. (2005). Evaluating the quality of informed consent. Clin. Trials 2, 34-41. doi: $10.1191 / 1740774505 \mathrm{cn} 066 \mathrm{oa}$

US Department of Health and Human Services. (2009). "Code of federal regulations," in Title 45 Part 46. Protection of Human Subjects. Washington, DC: U.S. Department of Health and Human Services.

World Medical Association [WMA]. (2008). Declaration of Helsinki: Ethical Principles for Medical Research Involving Human Subjects. Seoul: World Medical Association.

Zika, E., Paci, D., Schulte in Den Bäumen T., Braun, A., Sylvie, R.-D. Mylène, D. et al. (2010). Biobanks in Europe: Prospects for Harmonisation and Networking. EU-Report. Luxembourg: Institute for Prospective Technological Studies.

Conflict of Interest Statement: The authors declare that the research was conducted in the absence of any commercial or financial relationships that could be construed as a potential conflict of interest. 
Received: 07 August 2013; accepted: 24 October 2013; published online: 14 November 2013.

Citation: Hirschberg I, Knüppel H and Strech D (2013) Practice variation across consent templates for biobank research. A survey of German biobanks. Front. Genet. 4:240. doi: 10.3389/fgene.2013.00240

This article was submitted to ELSI in Science and Genetics, a section of the journal Frontiers in Genetics.
Copyright (c) 2013 Hirschberg, Knüppel and Strech. This is an open-access article distributed under the terms of the Creative Commons Attribution License (CC BY). The use, distribution or reproduction in other forums is permitted, provided the original author(s) or licensor are credited and that the original publication in this journal is cited, in accordance with accepted academic practice. No use, distribution or reproduction is permitted which does not comply with these terms. 